\title{
ORIGINAL ARTICLE \\ Inhibitory effects and molecular mechanisms of tetrahydrocurcumin against human breast cancer MCF-7 cells
}

\author{
Xiao Han, Shan Deng, Ning Wang, Yafei Liu and Xingbin Yang* \\ Key Laboratory of Ministry of Education for Medicinal Resource and Natural Pharmaceutical Chemistry, \\ College of Food Engineering and Nutritional Science, Shaanxi Normal University, Xi'an, China
}

\section{Abstract}

Background: Tetrahydrocurcumin (THC), an active metabolite of curcumin, has been reported to have similar biological effects to curcumin, but the mechanism of the antitumor activity of THC is still unclear.

Methods: The present study was to investigate the antitumor effects and mechanism of THC in human breast cancer MCF-7 cells using the methods of MTT assay, LDH assay, flow cytometry analysis, and western blot assay.

Results: THC was found to have markedly cytotoxic effect and antiproliferative activity against MCF-7 cells in a dose-dependent manner with the $\mathrm{IC}_{50}$ for $24 \mathrm{~h}$ of $107.8 \mu \mathrm{M}$. Flow cytometry analysis revealed that THC mediated the cell-cycle arrest at G0/G1 phase, and 32.8\% of MCF-7 cells entered the early phase of apoptosis at $100 \mu \mathrm{M}$ for $24 \mathrm{~h}$. THC also dose-dependently led to apoptosis in MCF-7 cells via the mitochondrial pathway, as evidenced by the activation of caspase- 3 and caspase-9, the elevation of intracellular ROS, a decrease in Bcl-2 and PARP expression, and an increase in Bax expression. Meanwhile, cytochrome $\mathrm{C}$ was released to cytosol and the loss of mitochondria membrane potential $(\Delta \psi \mathrm{m})$ was observed after THC treatment.

Conclusion: THC is an excellent source of chemopreventive agents in the treatment of breast cancer and has excellent potential to be explored as antitumor precursor compound.

Keywords: tetrahydrocurcumin; antitumor effect; cell cycle; apoptosis; mitochondria

Received: 3 December 2015; Revised: 7 January 2016; Accepted: 9 January 2016; Published: 17 February 2016

$\mathrm{B}$ reast cancer is the most common cancer in women, and it is the second leading cause of death in women after lung cancer (1). Large-scale epidemiological cohort studies have shown that dietary patterns, foods, and nutrients are closely associated with the risk for breast cancer (2). Indeed, studies have also shown that the ingestion of fruits and vegetables may reduce the risk of cancer, cardiovascular disease, and immunodysfunctions $(2,3)$. Due to the advantage of low toxicity and high efficacy, plant-derived foods play an increasing role in cancer chemoprevention and therapy (4). In recent years, naturally occurring 1,7-bis(4-hydroxy-3-methoxyphenyl)1E,6E-heptadiene-3,5-dione (curcumin) has been strongly investigated as the promising anticancer agent (5-8). Curcumin is a natural flavonoid and has been derived from the Curcuma longa, which is commonly used as a food-coloring agent (5). Interestingly, numerous studies suggested that curcumin had significant antitumor activities in vitro, while the antitumor effects in vivo were not significant, which might be related to its poor absorption $(9,10)$.
Tetrahydrocurcumin (THC), a major metabolite of curcumin, is a natural polyphenol in $C$. longa, and it has the identical $\beta$-diketone structure and phenolic groups, but curcumin lacks the double bonds (Fig. 1a) (11). Unlike curcumin, THC is stable in phosphate buffer saline at various $\mathrm{pH}$ values, and it is easily absorbed by the gastrointestinal tract, suggesting that THC may also play a crucial role in curcumin-induced biological effects, and may have the excellent potential to be developed into an antitumor precursor compound (12). However, the anticancer effects of THC remain poorly understood.

The present study was therefore designed to demonstrate the cytotoxicity of THC derived from $C$. longa in human breast cancer MCF-7 cell line, and to further investigate the possible cellular mechanisms by evaluating cell cycle distribution, intracellular ROS generation, and mitochondrial dysfunction. Our results suggested that THC induced G0/G1 arrest and apoptosis via the mitochondrial pathway in MCF-7 cells. These findings have important implications for the potential use of the 
(a)
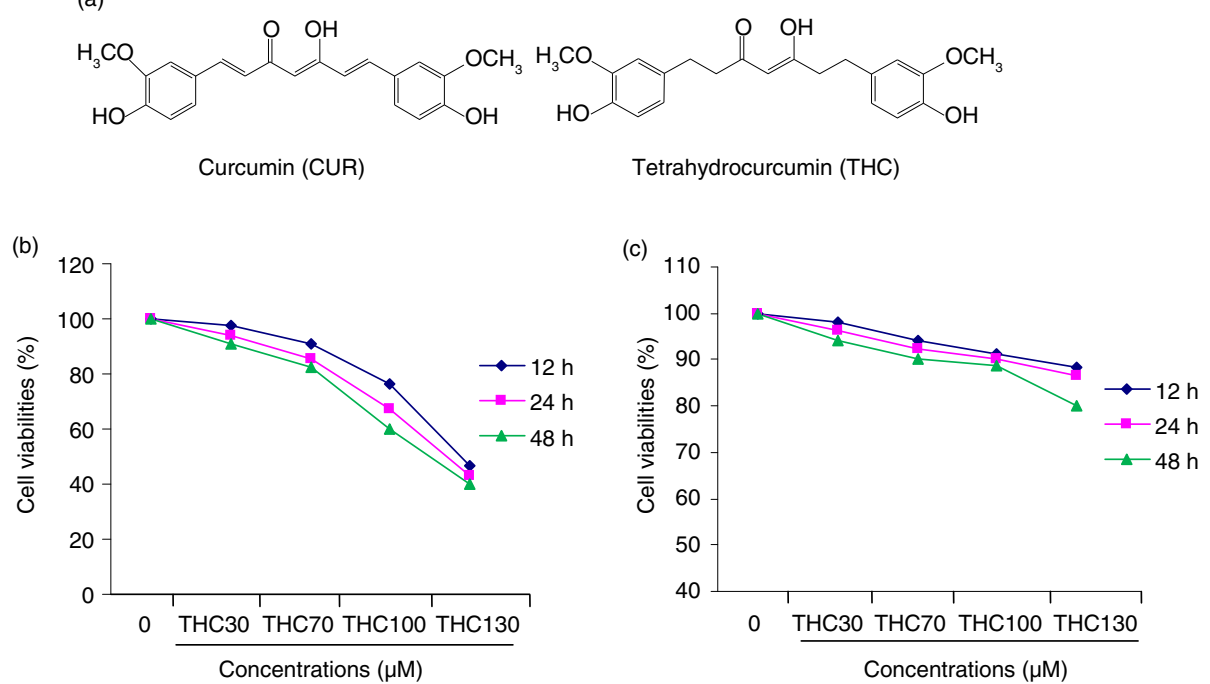

Fig. 1. Inhibitory effects of THC on cell proliferation in human breast carcinoma MCF-7 cells. (a) Chemical structures of THC and its parent curcumin (CUR), (b) antiproliferative effects of THC against MCF-7 cells, and (c) normal mammary epithelial cell H184B5F5/M10 cells. MCF-7 cells were treated with or without different concentrations of $\mathrm{THC}(0,30,70,100$, and $130 \mu \mathrm{M}$ ) for 12,24 , and $48 \mathrm{~h}$, respectively, and then the cell viability was assessed by MTT assay. Results are mean values $\pm \mathrm{SD}$ of three independent experiments. ${ }^{*} p<0.05$ and ${ }^{* *} p<0.01$ indicate statistically significant difference versus control group.

promising $\mathrm{THC}$ as a therapeutic or prophylactic treatment for cancer in humans.

\section{Materials and methods}

\section{Materials and chemicals}

Curcumin (CUR) and THC were obtained from Wuhan reagent company (Wuhan, China). Dimethylsulfoxide (DMSO), 5-fluoro-2,4 (1 h,3 h) pyrimidinedione (5-FU), 3-(4,5-dimethylthiazol-2-yl)-2,5-diphenyltetrazolium bromide (MTT), rhodamine 123 (Rh123), ethylenediaminetetraacetic acid (EDTA), RNAse-A and propidium iodide (PI), phenylmethyl-sulfonyl fluoride (PMSF), 4',6-diamidino-2phenylindole (DAPI), electro-chemi-luminescence (ECL), dichlorofluorescein diacetate (DCFH-DA), and tris- $\mathrm{HCl}$ and glycine were obtained from Sigma-Aldrich (St, Louis, MO, USA). Assay kits of BCA, caspase-3, caspase-9, and lactate dehydrogenase (LDH) were purchased from Nanjing Jiancheng Bioengineering Institute (Nanjing, China). Phosphate buffer solution (PBS), 0.1\% tween-20 in phosphate buffer solution (PBST), and sodium dodecyl sulfonate (SDS) were purchased from Zhengjiang Wanbang Pharmaceutical Co. (Wenling, China). The primary antibodies against Bax, Bcl-2, poly (ADP-ribose) polymerase (PARP), cytochrome $\mathrm{c}$, and the horseradish peroxidase (HPR)-conjugated goat anti-mouse secondary antibody were provided by BioVision, Inc., (BioVisio, Palo Alto, CA, USA). All the other cell culture reagents were purchased from Sinopharm (Beijing, China), and all the other chemicals were of analytical grade.

\section{Cell line and cell culture}

Human breast carcinoma cell MCF-7 line and normal mammary epithelial cell H184B5F5/M10 cell line were obtained from Cell Bank of Institute of Biochemistry and Cell Biology, Chinese Academy of Sciences (Shanghai, China). The cells were grown in RPMI 1640 medium with $10 \%$ fetal bovine serum and 1\% immune body. The cells were incubated at $37^{\circ} \mathrm{C}$ in a humidified incubator containing with $5 \% \mathrm{CO}_{2}$.

\section{Assay for cell viability}

The effect of THC on cell viability was determined by the MTT assay as previously described with some modifications (13). Cells were grown in a 96-well plate for $24 \mathrm{~h}$, and then the cells were incubated at 12, 24, and $48 \mathrm{~h}$ with various concentrations of THC. After the exposure period, $10 \mathrm{~mL}$ of MTT $(5.0 \mathrm{mg} / \mathrm{mL})$ in PBS solution was added to each well at a final concentration of $0.5 \mathrm{mg} / \mathrm{mL}$ and then the plate was further incubated for $4 \mathrm{~h}$. The supernatants were aspirated carefully, and the MTT-formazan crystals formed by metabolically viable cells were dissolved in $150 \mu \mathrm{L}$ of SDS. The absorbance was measured at $570 \mathrm{~nm}$ using an enzyme-linked immunosorbent assay (ELISA) reader (Rayto-RT6000, Guangdong, China).

\section{LDH assay for cytotoxicity}

Cytotoxicity was evaluated by $\mathrm{LDH}$ after the treatment with THC. The leakage into the media of $\mathrm{LDH}$, an indicator of cell membrane injury, was detected with an LDH kit (Jiancheng BioEngineering, Nanjing, China) 
according to the procedures described previously (14). Briefly, at the end of the incubation with indicated concentrations of THC for $24 \mathrm{~h}, 20 \mu \mathrm{L}$ of culture supernatants of MCF-7 cells or H184B5F5/M10 cells were taken out for the assay of extracellular LDH, which could catalyze the conversion of lactate to pyruvate, and then reacted with 2, 4-dinitrophenylhydrazine to show the brownish red color in basic solution. After reaction, the absorbance of each sample was read at wavelength 450 $\mathrm{nm}$, and the extracellular LDH activity was calculated as follows: $\mathrm{LDH}$ activity $(\mathrm{U} / \mathrm{L})=\left(\mathrm{OD}_{\text {test }}-\mathrm{OD}_{\text {control }}\right) /$ $\left(\mathrm{OD}_{\text {standard }}-\mathrm{OD}_{\text {blank }}\right) \times \mathrm{C}_{\text {standard }} \times \mathrm{N}_{\text {dilute times }} \times 1,000$.

\section{Morphological observation of nuclear change}

The MCF-7 cells were treated with various concentrations of THC, and the treated cells were washed with PBS and fixed in $4 \%$ paraformaldehyde for $30 \mathrm{~min}$ at room temperature, and then washed with PBS. The fixed cells were incubated with $1.0 \mu \mathrm{g} / \mathrm{mL}$ DAPI solution for $10 \mathrm{~min}$ at room temperature in the dark. Stained solution was washed out with PBS, and then the cells were observed with a fluorescence microscope (Leica DMIL LED, Leica, Germany) for determination of nuclear morphological change (15).

\section{Cell cycle analysis}

To determine the cell cycle distribution, MCF-7 cells were plated at a density of $1 \times 10^{5}$ cells/well in six-well plate, and were grown for $24 \mathrm{~h}$ at $37^{\circ} \mathrm{C}$ and $5 \% \mathrm{CO}_{2}$ in the presence of 0,70 and $100 \mu \mathrm{M}$ THC or 5 -FU $(50 \mu \mathrm{M})$. The cells were harvested and washed with PBS, and then the cells were fixed in $100 \mu \mathrm{L}$ of iced $70 \%$ ethanol at $-20^{\circ} \mathrm{C}$. The cells were left to stand overnight and then collected by centrifugation. Afterwards, the cells were resuspended in $1.0 \mathrm{~mL}$ PBS and $50 \mu \mathrm{L}$ ribonuclease and incubated at room temperature for $30 \mathrm{~min}$, and then $50 \mu \mathrm{L}$ PI was added and the cells were left to stand for another $30 \mathrm{~min}$. The cell cycle distribution was measured with flow cytometry (Millopore corporation, Billerica, MA, USA) (16).

\section{Cell apoptosis assay}

The extent of apoptosis was measured through Annexin V-FITC/PI double staining assay (17). Briefly, MCF-7 cells were treated with THC $(0,70,100 \mu \mathrm{M})$ or 5 -FU $(50 \mu \mathrm{M})$ for $24 \mathrm{~h}$, and then cells were collected, washed twice with PBS buffer, and stained with Annexin V-FITC and PI, followed by an assay using flow cytometry (Millopore corporation, Billerica, MA, USA). The number of intact cells, early apoptotic cells, and late apoptotic/necrotic cells were discriminated by counting the cells directly.

\section{ROS assay in MCF-7 cells}

Intracellular ROS production as hydrogen peroxide $\left(\mathrm{H}_{2} \mathrm{O}_{2}\right)$ was measured using dichlorofluorescein diacetate probes (18). Briefly, MCF-7 cells were seeded in 12-well plates and then exposed to a series concentration of THC for $24 \mathrm{~h}$. After incubation, the cells were detached with trypsin-EDTA and washed twice with PBS. The cells were immediately resuspended in $0.2 \mathrm{~mL}$ PBS containing DCFH-DA at the final concentration of $10 \mu \mathrm{M}$, and reacted at $37^{\circ} \mathrm{C}$ for $30 \mathrm{~min}$. ROS production of MCF-7 cells was evaluated by flow cytometry.

\section{Detection of mitochondrial membrane potential $(\Delta \psi \mathrm{m})$}

The mitochondrial membrane potential $(\Delta \psi \mathrm{m})$ was measured by flow cytometer using the cationic lipophilic green fluorochrome rhodamine 123 (19). MCF-7 cells were treated with various concentrations of THC for $24 \mathrm{~h}$ and the treated cells were harvested, washed twice with PBS, incubated with $1 \mathrm{mM}$ rhodamine 123 at $37^{\circ} \mathrm{C}$ for $30 \mathrm{~min}$, and washed twice with PBS. Fluorescence was determined by a Guava EasyCyte Plus Flow Cytometry System.

\section{Determination of caspase- 3 and caspase- 9 activities}

Caspase-3 and caspase-9 activities were assessed by Caspase Assay Kit (Jiancheng BioEngineering, Nanjing, China) according to the manufacturer's instruction. Control or treated cells were lysed in $100 \mu \mathrm{L}$ of cold lysis buffer containing 1.0 M dithiothreitol (DTT $10 \mu \mathrm{L} / \mathrm{mL}$ buffer) and incubated in ice for $15 \mathrm{~min}$. After centrifugation, supernatant containing about $20-40 \mu \mathrm{g}$ protein was mixed with $90 \mu \mathrm{L}$ detection buffer and $10 \mu \mathrm{L}$ catalytic substrate (ACDEVD-PNA specific for caspase-3 and AC-LEHD-PNA for caspase-9) in a 96-well microplate (20). All samples were incubated in $37^{\circ} \mathrm{C}$ for $2 \mathrm{~h}$. The absorbance representing the activities of caspases was measured at $405 \mathrm{~nm}$ with ELISA reader (Rayto-RT6000, Guang-dong, China).

\section{Total protein extraction and western blot assays}

MCF-7 cells were treated with THC at 70 and $100 \mu \mathrm{M}$ for $24 \mathrm{~h}$. For isolation of total protein fractions, the cells were collected, washed twice with cold PBS, and lysed with $0.1 \mathrm{~mL}$ of cold lysis buffer $(150 \mathrm{mM} \mathrm{NaCl}, 50 \mathrm{mM}$ of $\mathrm{pH} 7.4$ Tris, $1 \mathrm{mM}$ EDTA, $1 \%$ Trition X-100, $0.5 \%$ SDS, $0.01 \%$ PMSF) (21). The lysate was centrifuged at $12,000 \mathrm{~g}$ for $30 \mathrm{~min}$ at $4{ }^{\circ} \mathrm{C}$. Protein concentrations were determined with the BCA protein assay kit (Jiancheng BioEngineering, Nanjing, China). Total protein samples were separated by $12 \%$ SDS-PAGE and were transferred to a PVDF membrane. After non-specific binding sites were blocked with 5\% non-fat dry milk in PBS for $60 \mathrm{~min}$, transferred membrane was probed at $4^{\circ} \mathrm{C}$ overnight with primary antibodies (1:500). The membrane was washed with $0.1 \%$ tween-20 in PBS buffer, and then the membranes were probed for $1 \mathrm{~h}$ at room temperature with secondary antibody $(1: 5,000)$. Protein of interest was incubated with ECL detection reagent and developed by exposure to X-ray films. The protein expression was quantified densitometrically using Image 
J Software (version 1.43, National Institutes of Health, Bethesda, USA).

\section{Statistical analysis}

All the present data are expressed as mean \pm SD of three independent experiments. The significant difference from the respective control for each experimental test was assessed by one-way analysis of variance (ANOVA) using SPSS 19.0 software. The difference is considered significant if $p<0.05$.

\section{Results}

\section{THC inhibited cell proliferation of MCF-7 cells}

The inhibitory effect of THC against human breast cancer MCF-7 cells was determined by MTT assay. The inhibitory rate of MCF-7 cells treated with $\mathrm{THC}$ at 30, 70,100 , and $130 \mu \mathrm{M}$ for 12,24 , and $48 \mathrm{~h}$ was shown in Fig. 1b. It was found that THC significantly inhibited the growth of MCF-7 cells in a dose-dependent and timedependent manner. However, the antiproliferative effect of THC on H184B5F5/M10 normal mammary epithelial cells was not observed at the same test concentration for 12, 24 and $48 \mathrm{~h}$ (Fig. 1c. The results of MTT assay showed that THC had a markedly antiproliferative activity against the $\mathrm{MCF}-7$ cells in a dose-dependent manner with the $\mathrm{IC}_{50}$ for $24 \mathrm{~h}$ of $107.8 \mu \mathrm{M}$.

To further confirm the proliferation inhibitory effects of THC on MCF-7 cells, LDH assay was also performed

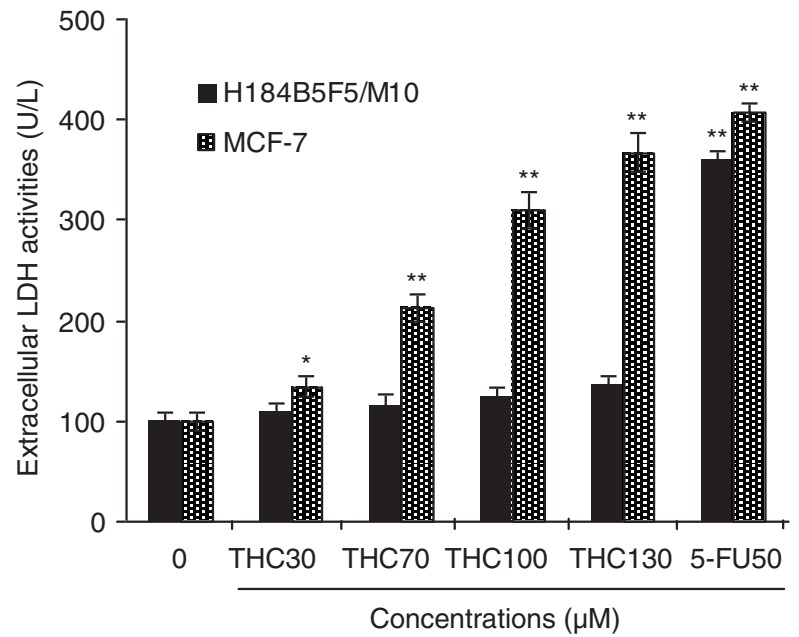

Fig. 2. Cytotoxicity of THC to MCF-7 cells. MCF-7 cells were incubated with different concentrations of THC $(0,30$, $70,100$, and $130 \mu \mathrm{M})$, and authorized 5-fluoro-2, 4 (1 h, $3 \mathrm{~h})$ pyrimidinedione $(5-\mathrm{FU}, 50 \mu \mathrm{M})$ was used as positive control for $24 \mathrm{~h}$, respectively. Cytotoxic effect was measured by LDH assay and expressed as U/L of LDH released from the MCF-7 cells after $24 \mathrm{~h}$ of incubation. All data were reported as the mean $\pm \mathrm{SD}$ of three separate experiments, and asterisks denote a statistical significance in comparison. as another indicator of THC-caused cytotoxicity to MCF-7 and H184B5F5/M10. As shown in Fig. 2, THC at $30,70,100$, and $130 \mu \mathrm{M}$ resulted in 1.3-, 2.1-, 3.1-, and 3.9 -fold $(p<0.01)$ increases over the untreated control in the LDH leakage from MCF-7 cells after $24 \mathrm{~h}$ of treatment, respectively. Moreover, compared with the untreated MCF-7 cells, the LDH leakage of 5-FU-treated MCF-7 cells has significantly increased, and the increase of THC at 100 and $130 \mu \mathrm{M}$ is close to the increase level of 5-FU. However, this cytotoxic effect was not observed in normal H184B5F5/M10 cells. Obviously, the observations implied that $\mathrm{MCF}-7$ cells exhibited a higher sensitivity to THC than H184B5F5/M10 cells, which were consistent with the MTT results. As a result, THC exerted high sensitivity to $\mathrm{MCF}-7$ cancer cells and might be amenable to further tests for molecular mechanism of its anticancer effects.

\section{THC-induced cell cycle arrest of MCF-7 cells}

To determine the mechanism of the antiproliferative effect of THC, cell cycle progression in MCF-7 cells was investigated. The percentages of cell cycle were measured by flow cytometry (22). As shown in Fig. 3a, THC induced a strong G0/G1 phase arrest in a dose-dependent manner $(p<0.05)$. When MCF-7 cells were incubated with 70 and $100 \mu \mathrm{M}$ THC and 5-FU for $24 \mathrm{~h}$, an accumulation of cell population in a $\mathrm{G} 0 / \mathrm{G} 1$ phase increased from $42.9 \%$ of the control group to 50.7, 60.2 and $64.9 \%$, accompanied by a decrease of the percentage of cells in the $\mathrm{S}$ phase from $50.4 \%$ of the untreated cells to $49.3,39.7$, and $31.2 \%$, respectively. Interestingly, the results of accumulation of cell population in G0/G1 phase and $S$ phase, which was treated with $100 \mu \mathrm{M}$ THC is similar to treated with 5-FU. However, THC at the tested concentrations did not have significant impact on the percentage of $\mathrm{G} 2 / \mathrm{M}$ phase cells $(p<0.05$, Fig. $3 \mathrm{~b})$. These results indicate that THC could result in G0/G1 phase arrest of MCF-7 cells, eventually inhibiting the growth of MCF-7 cells.

\section{Apoptotic induction on MCF-7 cells by THC}

To further confirm the apoptotic induction ability of THC, MCF-7 cells were stained with Annexin V-FITC and PI, followed by flow cytometry analysis. As shown in Fig. 4a, the control cells showed normal cell viability without significant cell apoptosis. When MCF-7 cells were treated with $70,100 \mu \mathrm{M}$ THC or 5-FU, the percentage of early apoptotic cells significantly raised by $8.3,37.8$, and $64.9 \%$, respectively, in contrast with control cells $(p<0.05$, $p<0.01$, Fig. 4b). As shown in Fig. 4b, THC at 70, $100 \mu \mathrm{M}$ and 5 -FU also caused 2.7, 7.0, and $21.8 \%$ of late necrotic/ apoptotic cells, respectively. Furthermore, a DNA-binding dye, DAPI, was also used for nuclear staining to elucidate apoptotic cell death due to the exposure of MCF-7 cells to $\mathrm{THC}$ and 5-FU (Fig. 4c). Under a fluorescence microscope, the normal cells with nuclear staining exhibited intact and round-shape nuclei, characterized by 

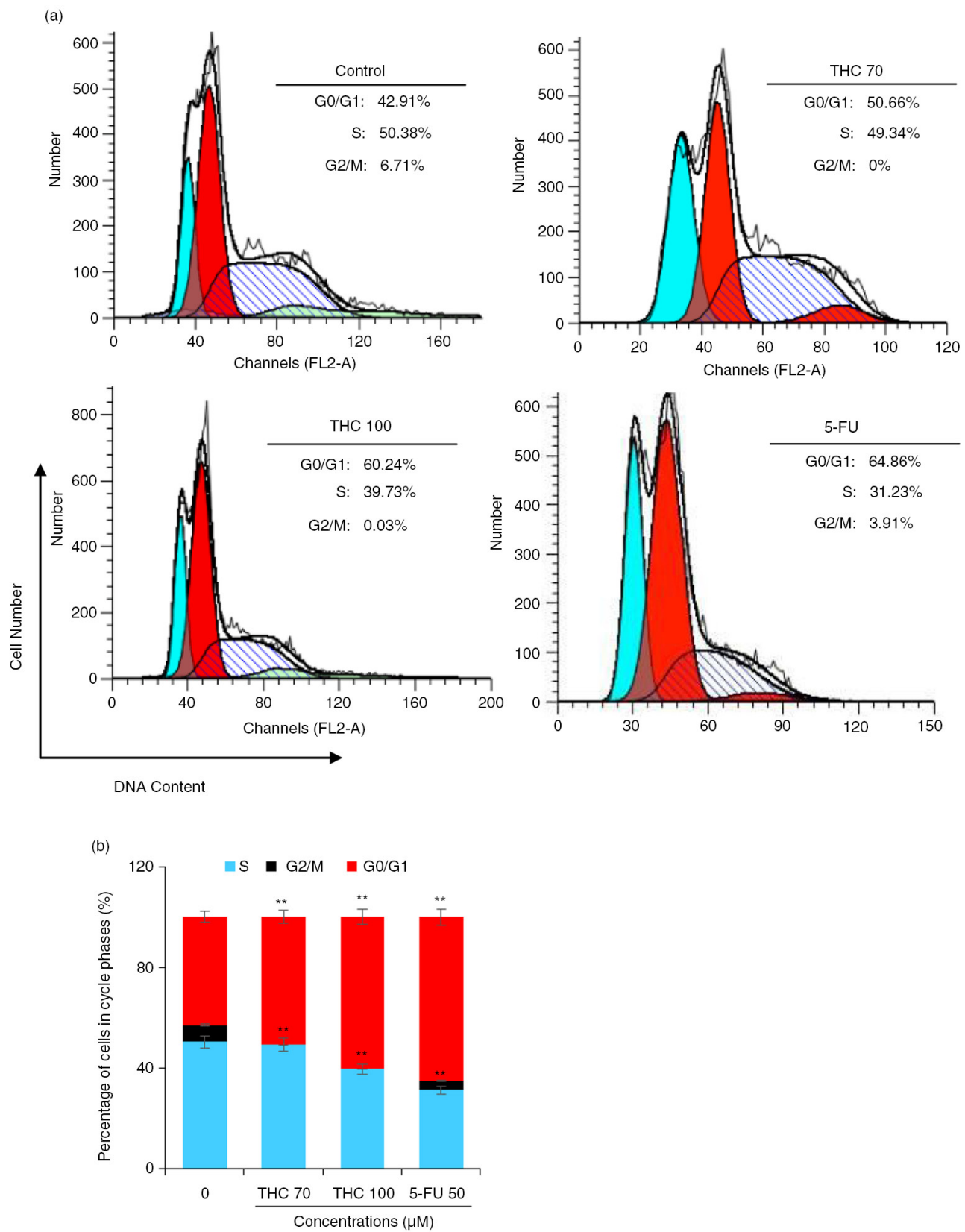

Fig. 3. Effects of THC on MCF-7 cell cycle distribution. (a) MCF-7 cells were treated with the tested THC, and the collected cells were stained with propidium iodide (PI) for $24 \mathrm{~h}$ after fixation by $75 \%$ of ethanol, and analyzed for DNA content by flow cytometry. (b) Representative histograms of DNA content and cell cycle phases (G0/G1, S, and G2/M) in MCF-7 cells treated with 70, $100 \mu \mathrm{M}$ THC and authorized 5-FU $(50 \mu \mathrm{M})$ was used as positive control for $24 \mathrm{~h}$, as shown. Horizontal and vertical axes indicate the relative nuclear DNA content and number of cells, respectively. Ratios of various cell cycle phases including G0/G1, $\mathrm{S}$, and $\mathrm{G} 2 / \mathrm{M}$ were presented. Data were shown as the means mean $\pm \mathrm{SD},{ }^{*} p<0.05$ and ${ }^{* *} p<0.01$ as compared to control.

the slight staining because of euchromatin in MCF-7 cells. In contrast, the exposure to $\mathrm{THC}$ at 70 and $100 \mu \mathrm{M}$ for $24 \mathrm{~h}$ altered MCF-7 cellular nuclear morphology with increased, condensed, or fragmental chromatin, which is characteristic of apoptotic cells culminating in chromatin condensation and nuclear fragmentation (23). Besides, the cellular nuclear morphology with the treatment of $100 \mu \mathrm{M}$ THC is close to the treatment of $5-\mathrm{Fu}$.

\section{THC triggered a marked loss of $\Delta \psi m$}

Here, we further evaluated whether THC treatment had any effects on the $\Delta \psi \mathrm{m}$, which was critical in cells undergoing apoptosis (23). We monitored the potential gradient across the membrane using the fluorescent dye RH123 (Fig. 5a). As shown in Fig. 5b, when MCF-7 cells were treated with $0,70,100 \mu \mathrm{M}$ THC or 5 -FU for $24 \mathrm{~h}$, the population that lost $\Delta \psi \mathrm{m}$ was increased from 

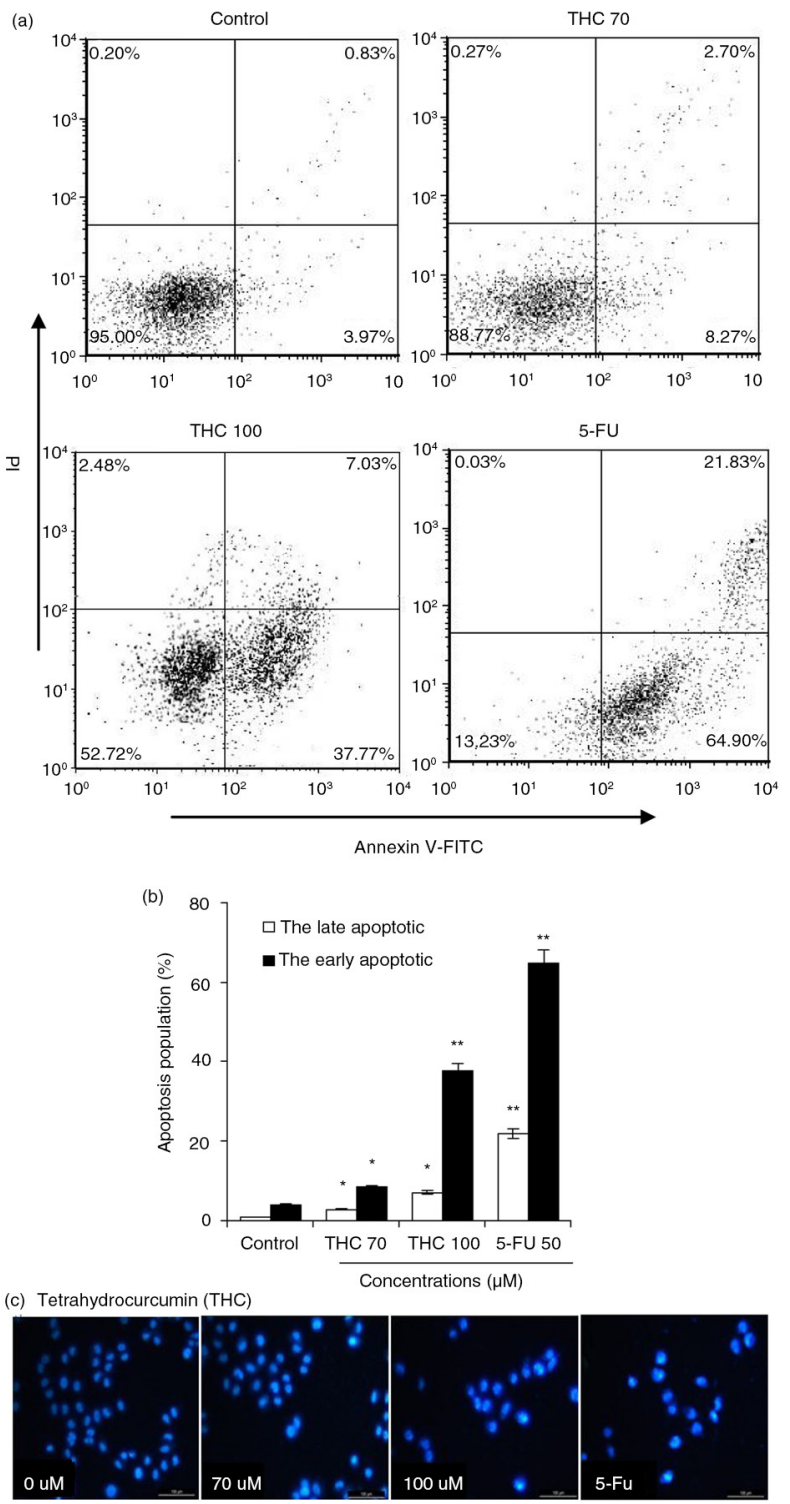

Fig. 4. THC-induced apoptosis on MCF-7 cells. (a) MCF-7 cells were treated with different concentrations of THC $(0,70$, and $100 \mu \mathrm{M})$, and authorized $5-\mathrm{FU}(50 \mu \mathrm{M})$ was used as positive control. After $24 \mathrm{~h}$ of treatment, effects of THC on cell apoptosis necrosis of MCF-7 cells were assessed by flow cytometry. Representative dot plots of Annexin V-FITC/PI staining are shown for the tested compounds. (b) The percentage of apoptotic cells was calculated from the ratio of early apoptotic cells at $24 \mathrm{~h}$ of exposure of THC. (c) MCF-7 cells were treated with $0,70,100 \mu \mathrm{M}$ THC for $24 \mathrm{~h}$. Morphological changes were determined by fluorescence microscope. All experiments were done independently in triplicate per experimental point, and representative results are shown. Statistically significant difference is indicated at ${ }^{*} p<0.05$ or $* * p<0.01$ level.

$4.1 \%$ of the untreated cells to $9.9,17.4$, and $49.6 \%$, respectively $(p<0.05, p<0.01)$, suggesting that THC could lead to a concentration-dependent dysfunction in mitochondria.

\section{Effect of THC on caspase-3 and caspase- 9 activities in MCF-7 cells}

Caspase protease family is believed to play a central role in mitochondria-mediated apoptotic responses (18). To investigate the apoptotic pathway in THC-treated MCF-7 cells, we examined the caspase- 3 and caspase- 9 activities. As showed in Fig. 6a, both caspase-3 and caspase- 9 were significantly activated by THC. Meanwhile, the activity of caspase- 9 in the MCF-7 cells treated with THC at 70, $100 \mu \mathrm{M}$, and 5-FU increased by 1.2-fold $(p<0.05), 1.4$-fold $(p<0.01)$, and 1.7-fold $(p<0.01)$, respectively, compared to control cells. Analogously, intracellular caspase-3 activity was also enhanced with the treatment of $\mathrm{THC}$ at 70 and $100 \mu \mathrm{M}(p<0.05)$. These results demonstrated that the THC-induced activation of caspase- 3 or caspase- 9 was involved in mitochondriamediated apoptosis in MCF-7 cells.

\section{Effects of THC on the expression of apoptosis-related proteins}

Mitochondria-mediated apoptosis is the best known intrinsic apoptosis pathway (24). To determine whether the mitochondrial apoptotic proteins was involved in THC-induced apoptosis, expression patterns of proapoptotic and anti-apoptotic Bcl-2 family proteins, cytochrome c, and PARP in THC-treated MCF-7 cells were investigated by western blot. As depicted in Fig. 6b, THC at 70 and $100 \mu \mathrm{M}$ significantly downregulated the expression of anti-apoptotic protein Bcl-2, whereas the expression of pro-apoptotic protein Bax was upregulated with the increasing concentrations of $\mathrm{THC}$ treatment. At the same time, the content of cytochrome $\mathrm{c}$ in cytosol was also significantly increased, whereas cytochrome c levels in mitochondria was decreased following THC treatment. Moreover, it was also found that THC caused a slight increase in the cleavage of PARP in MCF-7 cells, indicating that mitochondrial pathway is involved in $\mathrm{THC}$-induced apoptosis.

\section{The role of ROS in THC-induced apoptosis}

The escalated ROS level in the mitochondria can already push cancer cells to the brink of their toxic threshold, which is implicated in the induction of apoptosis by several flavonoids (24). Herein, we speculated that the cell growth inhibition of THC might be partly due to additional increased intracellular ROS generation, perturbing cellular redox homeostasis. To test this hypothesis, we next measured intracellular ROS in terms of fluorescence by DCF. As depicted in Fig. 7a, the green fluorescence intensities of DCF signals were significantly enhanced with the addition of THC. As supposed, $70,100 \mu \mathrm{M}$ THC, and 5-FU separately resulted in the production of $\mathrm{H}_{2} \mathrm{O}_{2}$ by $18.2,50.7$, and $67.2 \%$, respectively, in MCF-7 cells, compared with untreated control $(2.2 \%, p<0.01$, Fig. $7 b)$. The data present here indicated 
(a)
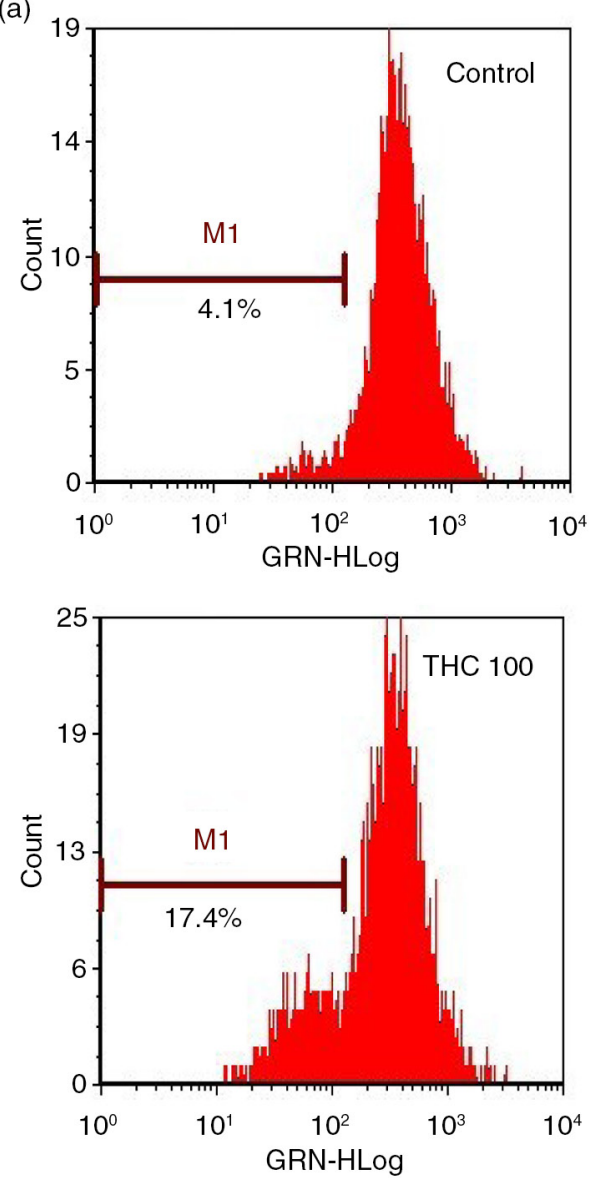
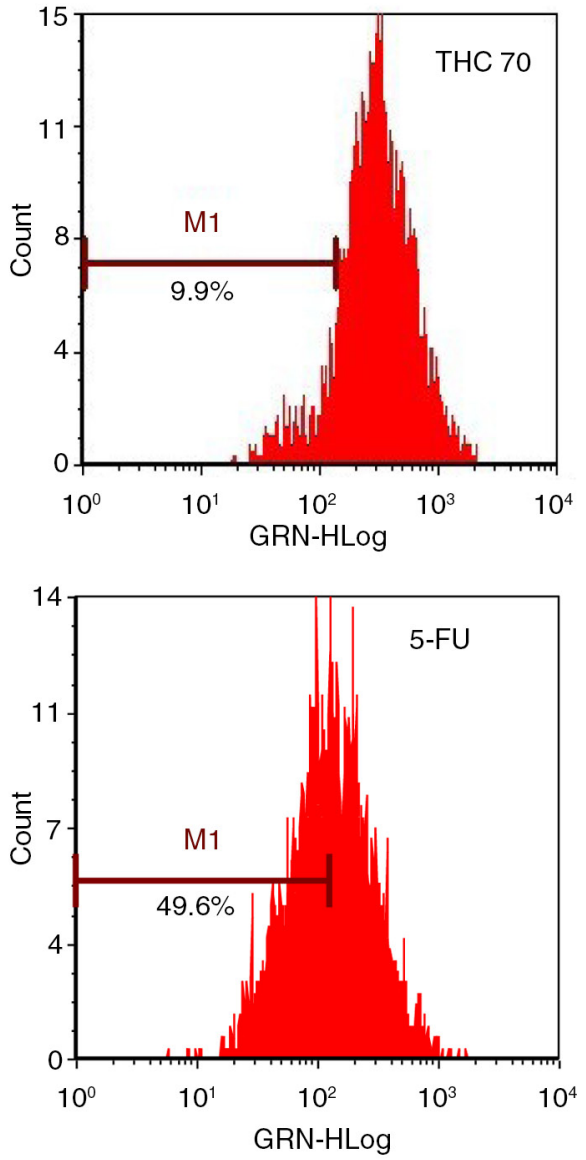

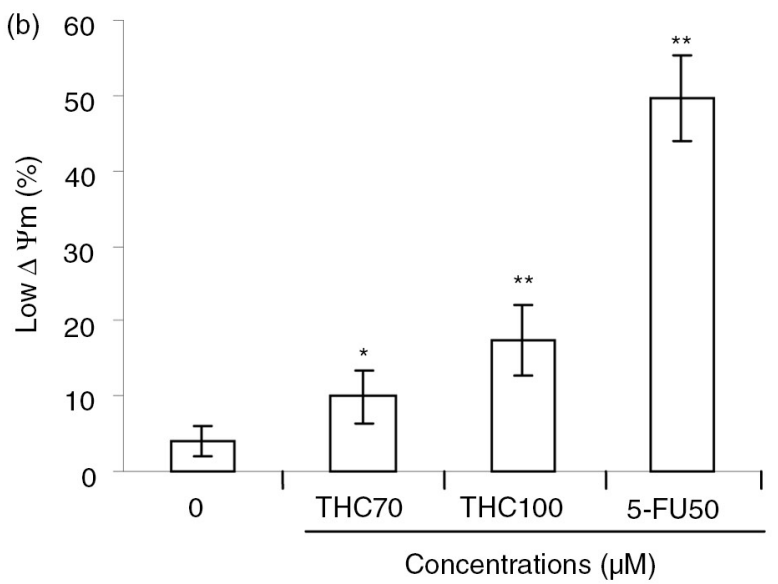

Fig. 5. Effects of THC on mitochondrial membrane potential $(\Delta \psi \mathrm{m})$ in MCF-7 cells. (a) Evaluation of mitochondria membrane potential $(\Delta \psi \mathrm{m})$ in MCF-7 cells was done with Rhodamine 123 stain by flow cytometry. (b) The percentage of M1 reflects the reduction of $\Delta \psi \mathrm{m}$. All experiments were done independently in triplicate per experimental point, and representative results are shown. All data represent as the mean $\pm \mathrm{SD}$ of three independent experiments. ${ }^{*} p<0.05$ and ${ }^{* *} p<0.01$ versus control.

that MCF-7 cells treated with THC exhibited a rapid response in the generation of intracellular $\mathrm{H}_{2} \mathrm{O}_{2}$, relative to basal levels of ROS. These results suggest that THC may induce growth inhibition and apoptosis through enhancing intracellular ROS oxidative stress of MCF-7 cancer cells.

\section{Discussion}

In recent years, it has been reported that curcumin exhibits antineoplastic activities in vivo and in vitro (25-27). However, the pharmacokinetic features of curcumin in several species have indicated poor systemic bioavailability, which may be related to its inadequate absorption (11). 
(a)

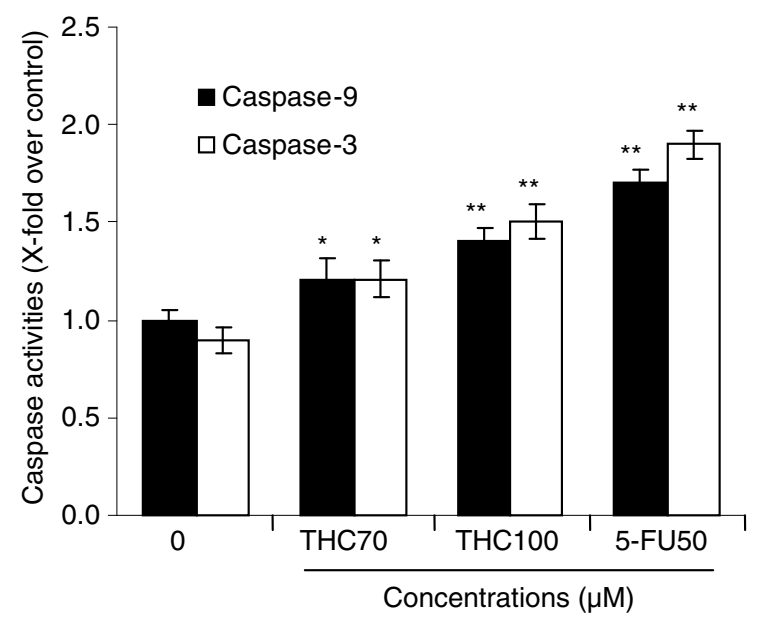

(b)
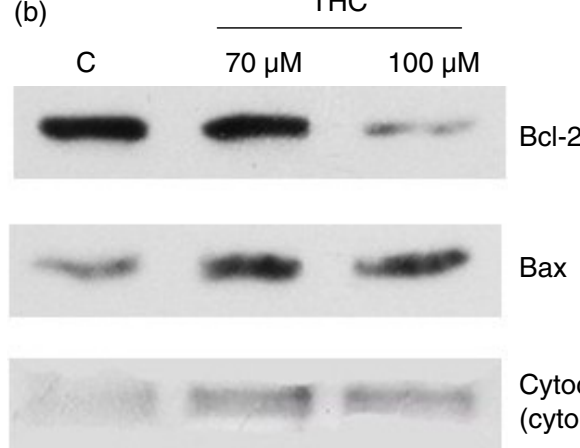

Cytochrome C (cytoplasm)

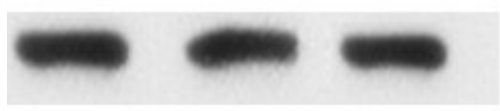

PARP

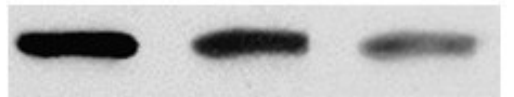

Cytochrome C (mitochondria)

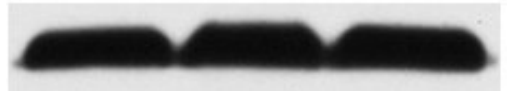

$\beta$-action

Fig. 6. THC-induced mitochondrial apoptotic pathway. (a) Quantitative analysis of caspase- 9 activity and caspase-3 activity was performed using synthetic caspase substrates Ac-LEHD- $p$ NA and Ac-DEVD- $p$ NA. Data in the figure represent mean $\pm \mathrm{SD}$ of three independent experiments. ${ }^{*} p<0.05$ and ${ }^{* *} p<0.01$ indicate that those groups differ significantly from the control. (b) The protein expression was determined with or without THC by western blot ( $\beta$-action as loading control). THC-induced upregulation of Bax, cytochrome c, and PARP, and downregulation of Bcl-2 by western blotting assay. MCF-7 cells were treated with THC at 0,70 , and $100 \mu \mathrm{M}$ for $24 \mathrm{~h}$. The test was repeated three times and representative blots are shown.

Therefore, we speculate that THC, a key phase I metabolite of curcumin, might be one of the genuine effective forms of curcumin in vivo to contribute to the pharmacological effects against human breast cancer.
Interestingly, THC has recently been reported to induce autophagy in human leukemia HL-60 cells (28), and it also inhibits HT1080 cell invasion and motility (12). However, there is little knowledge regarding the potency and mechanism of THC against breast cancer. In order to better understand the mechanism of apoptosis induced by THC, we investigated the effects of this compound on human breast cancer MCF-7 cells. Here, the molecular mechanism underlying THC-induced apoptosis is currently being elucidated, and THC was shown to have cytotoxic effect against MCF-7 cells via inducing G0/G1 arrest and mitochondria-mediated apoptosis.

Recent research has demonstrated that flavonoids cause growth inhibition to human cancer cells through interfering with the cell cycle progress (29). It is also well known that apoptosis and cell cycle deregulation are closely related events, and disruption of cell cycle progression may ultimately lead to apoptotic/necrotic death (15). In our cell cycle analysis, THC consistently exhibited effective cell growth inhibition by inducing cancer cells to undergo G0/G1 phase arrest in MCF-7 cells (Fig. 3). However, our findings were not in agreement with other previously reports, which showed that curcumin inhibited the cell cycle progression of gastric cancer cells at G2/M in HL-60 cells and MCF-7 cells cycle (29). Differences in the tested responses are most likely due to the specific cell type and concentration and treatment time used. Furthermore, there is mounting evidence that chemotherapeutic agents induce tumor regression through induction of apoptosis (28). In this study, the apoptosis induction ability of THC was confirmed and quantified by FACS analysis after staining with Annexin V-FITC/ PI. A cell population with Annexin V positive and PI negative is considered as an early apoptotic population, whereas a cell population with both annexin V and PI positive is considered as a late apoptotic/necrotic population (30). As depicted in Fig. 4, the results from annexin V/PI co-staining assay clearly demonstrated that THC induced apoptosis in MCF-7 cells, as reflected by the fact that the late apoptotic cells were concomitantly increased with the increased time of THC treatment. This finding was further confirmed by many morphological and biochemical changes that happened during apoptosis, including cell shrinkage, formation of apoptotic bodies, and nuclear condensation in the cancer cells treated with THC (Fig. 4). Our result is in agreement with earlier investigations showing that curcumin causes growth inhibition in human cancer cells by interfering with the cellular apoptosis progress (13).

Mitochondrial pathway is thought to be the major pathway for apoptosis, and therefore, targeting the mitochondria is a novel strategy for cancer therapy (31). Mitochondria-mediated apoptosis is highly regulated by the Bcl-2 family protein comprising both anti-apoptotic (Bcl-2) and pro-apoptotic members (Bax), and the 
(a)
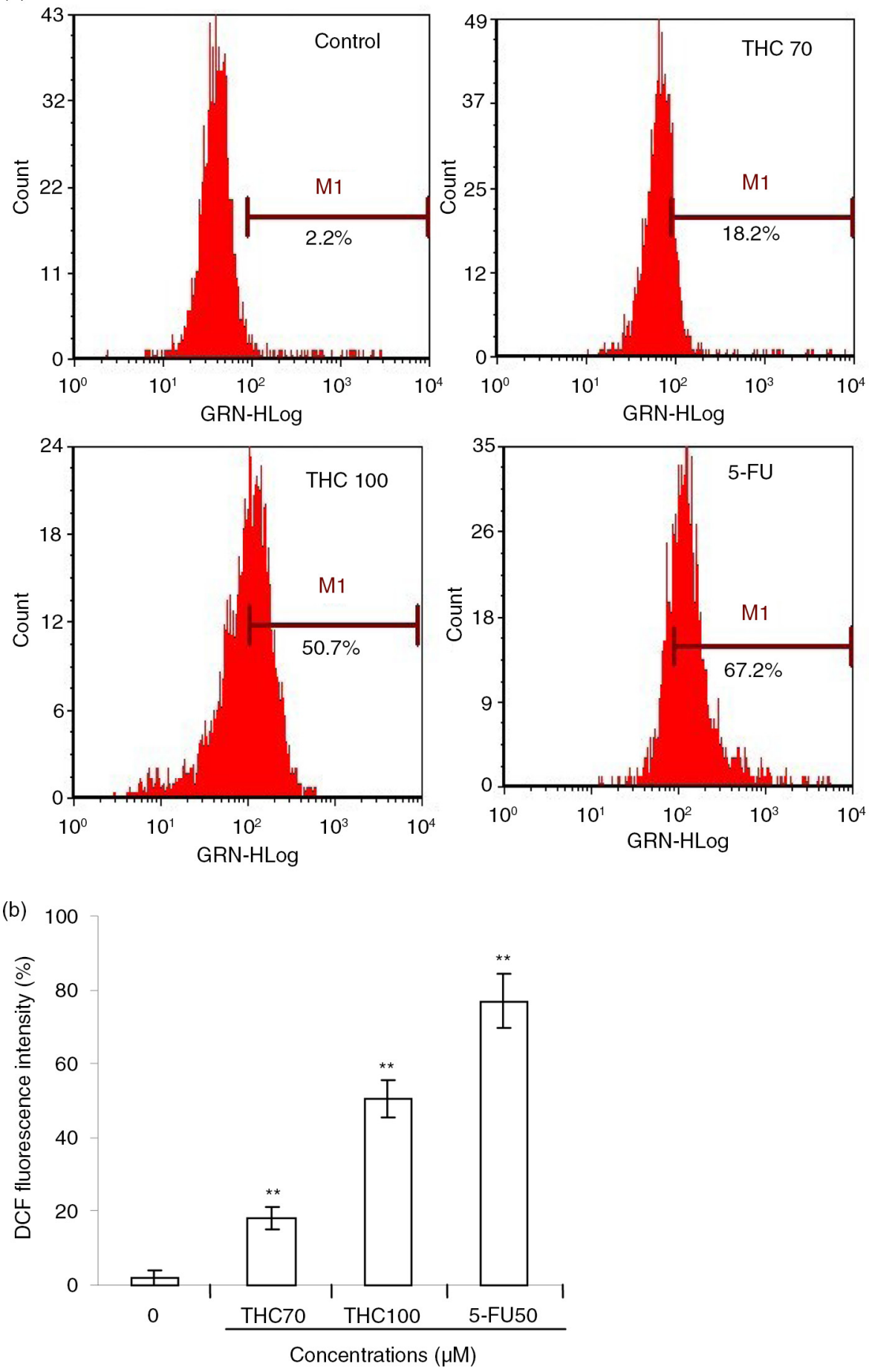

Fig. 7. Effects of THC on intracellular ROS generation in MCF-7 cells. (a) MCF-7 cells were treated with $0,70,100 \mu \mathrm{M}$ THC or 5-FU $(50 \mu \mathrm{M})$ for $24 \mathrm{~h}$, and then stained with DCFH-DA $(10 \mu \mathrm{M})$, followed by an assay by flow cytometry. (b) ROS in the cells converts the non-fluorescent dye into fluorescein, which emits green fluorescence. Fluorescence intensity is an indication of ROS levels in MCF-7 cells. All data represent the mean $\pm \mathrm{SD}$ of three independent experiments. $* * p<0.01$ versus control.

balance between the expression levels of pro-apoptotic and anti-apoptotic proteins is critical for cell survival or cell death $(19,32)$. Mitochondrial dysfunction usually triggers some cellular signaling to induce apoptosis, and mitochondrial transmembrane potential $(\Delta \psi \mathrm{m})$ decreasing and cytochrome c releasing to cytosol are two common parameters of mitochondrial dysfunction (33). As demonstrated by using RH123 staining, there was a decrease in RH123 fluorescence after treatment with $\mathrm{THC}$ as early as $24 \mathrm{~h}$ in comparison with the untreated 
cells, indicating that THC-induced $\Delta \psi \mathrm{m}$ disruption in MCF-7 cells. Meanwhile, we also found that cytochrome c was released from the mitochondria to the cytosol (Fig. 6b). In addition, the caspase protein family is believed to play a central role in mediating various apoptotic responses (34). Caspases include two types of subfamilies, namely upstream initiator caspases (e.g. caspase-8 and capase-9) and downstream effector caspases (e.g. caspase-3), which are responsible for the activation of the executioner caspases within the mitochondrial pathway of apoptosis (34). In the cytoplasm, cytochrome c, together with caspase-9, constitutes a proteolytic active complex called apoptosome to activate caspase-3, and eventually provokes apoptosis $(35,36)$. It had also been reported that Bax, PARP, caspase- 3 and caspase- 9 were increased, and Bcl-2 and $\Delta \psi \mathrm{m}$ were decreased in curcumin-treated MCF-7 cells, leading to apoptosis (37). Here, we found that THC decreased $\Delta \psi \mathrm{m}$ and Bcl-2 expression (Figs. 5 and 6), and increased Bax expression (Fig. 6b), which could be responsible for THC-induced apoptotic process. Furthermore, cytochrome $\mathrm{c}$ was found to be released from mitochondria to the cytosol. It is widely recognized that the cleavage of PARP, which is one of the substrates for caspase-3, is an early and critical event required for tumor cells apoptosis (35). In our hands, the activation of caspase- 3 and the cleavage of PARP were clearly observed, indicating that apoptosis induced by THC in MCF-7 cells occurred via mitochondria-dependent signal pathway.

In mammalian cells, increased cellular ROS production has been suggested to be responsible for the depolarization of mitochondrial $\Delta \psi \mathrm{m}$ and subsequent cell apoptosis, and some flavonoids are recently shown to stimulate cellular oxidative metabolism (38). Mitochondria are well known to be a source of ROS during apoptosis, and previous studies indicate that the ROS generation is an upstream factor for regulating apoptosis (39). To confirm if the mitochondrial dysfunction observed in MCF-7 cells treated with THC was promoted by ROS production, we measured ROS levels using the cell-permeable dye DCF-DA. The results showed that the apoptotic effect of THC against MCF-7 cells was associated with an elevated level of intracellular ROS in a concentration-response manner. As showed in Fig. $7 \mathrm{~b}$, the levels of $\mathrm{H}_{2} \mathrm{O}_{2}$ in 70 and $100 \mu \mathrm{M}$ of THC-treated and 5-Fu-treated cells for $24 \mathrm{~h}$ were elevated by $18.2,50.7$, and $76.9 \%$, respectively, compared with the untreated control cells. These results suggest that ROS-dependent mechanism may be involved in THC-induced apoptosis, and ROS-independent mechanism needs to be further investigated in the future.

In conclusion, this is the first study to show that THC, a major metabolite of curcumin, may be one of the active antitumor forms of curcumin, and it is able to exhibit anti-proliferation of human breast cancer MCF-7 cells via cell cycle arrest at the G0/G1 phase and apoptosis induced by ROS-dependent mitochondrial pathway. The observed antitumor effect indicates the possibility that THC may provide an effective and alternative treatment strategy for cancer. Understanding the involvement of the active THC in human cancer treatment is an attractive challenge and requires further investigation.

\section{Acknowledgements}

This study was supported by a grant from the National Natural Science Foundation of China (C31171678) and the Fundamental Research Funds for the Central Universities of Shaanxi Normal University, China (GK201103004).

\section{Conflict of interest and funding}

The authors have not received any funding or benefits from industry or elsewhere to conduct this study.

\section{References}

1. Liang S, Singh M, Dharmaraj S, Gam LH. The PCA and LDA analysis on the differential expression of proteins in breast cancer. Dis Markers 2010; 29: 231-42.

2. Block G, Patterson B, Subar A. Fruit, vegetables, and cancer prevention: a review of the epidemiological evidence. Nutr Cancer 1992; 18: 1-29.

3. Joshipura KJ, Hu FB, Manson JE, Stampfer MJ, Rimm EB, Speizer FE, et al. The effect of fruit and vegetable intake on risk of coronary heart disease. Ann Intern Med 2001; 134: 1106-14.

4. Boyer J, Brown D, Liu RH. Uptake of quercetin and quercetin 3 -glucoside from whole onion and apple peel extracts by Caco-2 Cell monolayers. J Agric Food Chem 2004; 52: 7172-9.

5. Aggarwal BB, Sung B. Pharmacological basis for the role of curcumin in chronic diseases: an age-old spice with modern targets. Trends Pharmacol Sci 2009; 30: 85-94.

6. Sun SH, Huang HC, Huang C, Lin JK. Cycle arrest and apoptosis in MDA-MB-231/Her2 cells induced by curcumin. Eur J Pharmacol 2012; 690: 22-30.

7. Singh S. From exotic spice to modern drug. Cell 1999; 130: 765-8.

8. Priyadarsini KI. Free radical reactions of curcumin in membrane model. Free Radic Biol Med 2007; 23: 838-46.

9. Kuo ML, Huang TS, Lin JK. Curcumin, an antioxidant and anti-tumor promoter, induces apoptosis in human leukemia cells. Biochem Biophys Acta 1996; 1317: 95-100.

10. Anto RJ, Mukhopadhyay A, Denning K, Aggarwal BB. Curcumin (diferuloylmethane) induces apoptosis through activation of caspase- 8 , BID cleavage and cytochrome c release: its suppression by ectopic expression of $\mathrm{Bcl}-2$ and $\mathrm{Bcl}-\mathrm{xl}$. Carcinogenesis 2002; 23: 143-50.

11. Okada K, Wangpoengtrakul C, Tanaka T, Toyokuni S, Uchida $\mathrm{K}$, Osawa T. Curcumin and especially tetrehydrocurcumin ameliorate oxidative stress-induced renal injury in mice. J Nutr 2001; 31: 2090-5.

12. Yodkeeree S, Garbisa S, Limtrakul P. Tetrahydrocurcumin inhibits HT1080 cell migration and invasion via downregulation of MMPs and uPA. Acta Pharmacol Sin 2008; 29: 853-60.

13. Zhao XC, Zhang L. Curcumin protects mouse neuroblastoma Neuro-2A cells against hydrogen-peroxide-induced oxidative stress. Food Chem 2011; 129: 387-94.

14. Yu CH, Kan SF, Shu CH, Lu TJ, Sun-Hwang L, Wang PS. Inhibitory mechanisms of Agaricus blazei Murill on the growth 
of prostate cancer in vitro and in vivo. J Nutr Biochem 2009; 20: 753-64.

15. He N, Shi X, Zhao Y, Tian L, Wang D, Yang X. Inhibitory effects and molecular mechanisms of selenium-containing tea polysaccharides on human breast cancer MCF-7 cells. J Agric Food Chem 2013; 61: 579-88.

16. Marel AK, Lizard G, Izard JC, Latruffe N, Delmas D. Inhibitory effects of trans-resveratrol analogs molecules on the proliferation and the cell cycle progression of human colon tumoral cells. Mol Nutr Food Res 2008; 52: 538-48.

17. Jaramillo S, Lopez S, Varela LM, Rodriguez-Arcos R, Jimenez A, Abia R, et al. The flavonol isorhamnetin exhibits cytotoxic effects on human colon cancer cells. J Agric Food Chem 2010; 58: 10869-75.

18. Son YO, Hitron JA, Wang X, Chang Q, Pan J, Zhang Z, et al. $\mathrm{Cr}(\mathrm{VI})$ induces mitochondrial-mediated and caspase-dependent apoptosis through reactive oxygen species-mediated p53 activation in JB6 Cl41 cells. Toxicol Appl Pharmacol 2010; 245: 226-35.

19. Chidambara Murthy KN, Jayaprakasha GK, Kumar V, Rathore KS, Patil BS. Citrus limonin and its glucoside inhibit colon adenocarcinoma cell proliferation through apoptosis. J Agric Food Chem 2011; 59: 2314-23.

20. Yin MC, Lin CC, Wu HC, Tsao SM, Hsu CK. Apoptotic effects of protocatechuic acid in human breast, lung, liver, cervix, and prostate cancer cells: potential mechanisms of action. J Agric Food Chem 2009; 57: 6468-73.

21. Shi X, Zhao Y, Jiao Y, Shi T, Yang X. ROS-dependent mitochondria molecular mechanism underlying antitumor activity of Pleurotus abalonus acidic polysaccharides in human breast cancer MCF-7 cells. PloS One 2013; 8: 1-12.

22. Kang TB, Liang MC. Studies on the inhibitory effects of quercetin on the growth of HL460 leukemia cells. Biochem Pharmacol 1997; 54: 1013-18.

23. Wyllie AH, Kerr JF, Currie AR. Cell death: the significance of apoptosis. Int Rev Cytol 1980; 68: 251-306.

24. Sun Y, Mu F, Li C, Wang W, Luo M, Fu Y, et al. Aspidin BB, a phloroglucinol derivative, induces cell cycle arrest and apoptosis in human ovarian HO-8910 cells. Chem Biol Interact 2013; 204: 88-97.

25. Duvoix A, Blasius R, Delhalle S, Schnekenburger M, Morceau F, Henry E, et al. Chemopreventive and therapeutic effects of curcumin. Cancer Lett 2005; 223: 181-90.

26. Masuelli L, Benvenuto M, Fantini M, Marzocchella L, Sacchetti P, Di Stefano E, et al. Curcumin induces apoptosis in breast cancer cell lines and delays the growth of mammary tumors in neu transgenic mice. J Biol Regul Homeost Agents 2013; 27: 105-19.

27. Kössler S, Nofziger C, Jakab M, Dossena S, Paulmichl M. Curcumin affects cell survival and cell volume regulation in human renal and intestinal cells. Toxicology 2012; 292: 123-35.
28. Wu JC, Lai CS, Badmaev V, Nagabhushanam K, Ho CT, Pan MH. Tetrahydrocurcumin, a major metabolite of curcumin, induced autophagic cell death through coordinative modulation of PI3K/Akt-mTOR and MAPK signaling pathways in human leukemia HL-60 cells. Mol Nutr Food Res 2011; 55: 1646-54.

29. Bartek J, Lukas C, Lukas J. Checking on DNA damage in S phase. Nat Rev Mol Cell Biol 2004; 5: 792-804.

30. Zou YP, Chang SKC. Effect of black soybean extract on the suppression of the proliferation of human AGS gastric cancer cells via the induction of apoptosis. J Agric Food Chem 2011; 59: 4597-605.

31. Fulda S, Galluzzi L, Kroemer G. Targeting mitochondria for cancer therapy. Nat Rev Drug Discov 2010; 9: 447-64.

32. Hengartner M. The biochemistry of apoptosis. Nature 2000; 407: 770-6.

33. Mehmet H. Apoptosis: caspase find a new place to hide. Nature 2002; 403: 29-30.

34. Indran IR, Tufo G, Pervaiz S, Brenner C. Recent advances in apoptosis, mitochondria and drug resistance in cancer cells. Biochim Biophys Acta 2011; 1807: 735-45.

35. Yoo L, Hong S, Shin KS, Kang SJ. PARP-1 regulates the expression of caspase-11. Biochem Biophys Res Commun 2011; 408: 489-93.

36. Mohan S, Abdul AB, Abdelwahab SI, Al-Zubairi AS, Sukari MA, Abdullah R, et al. Typhonium flagelliforme induces apoptosis in CEMss cells via activation of caspase-9, PARP cleavage and cytochrome c release: its activation coupled with G0/G1 phase cell cycle arrest. J Ethnopharmacol 2010; 131: 592-600.

37. Kizhakkayil J, Thayyullathil F, Chathoth S, Hago A, Patel M, Galadari S. Modulation of curcumin-induced Akt phosphorylation and apoptosis by $\mathrm{P} 13 \mathrm{~K}$ inhibitor in MCF-7 cells. Biochem Biophys Res Commun 2010; 394: 476-81.

38. Fan J, Cai H, Yang S, Yan L, Tan W. Comparison between the effects of normoxia and hypoxia on antioxidant enzymes and glutathione redox state in ex vivo culture of CD34+ cells. Comp Biochem Physiol 2008; 151: 153-8.

39. Sreelatha S, Jeyachitra A, Padma PR. Antiproliferation and induction of apoptosis by Moringa oleifera leaf extract on human cancer cells. Food Chem Toxicol 2011; 49: 1270-5.

\footnotetext{
*Xingbin Yang

College of Food Engineering and Nutritional Science

Shaanxi Normal University

Xi'an 710062, China

Email: xbyang@snnu.edu.cn
} 